\title{
THE INFLUENCE OF PHARMACIST COUNSELING ON CHANGES IN HEMOGLOBIN LEVELS OF PREGNANT WOMEN AT A COMMUNITY HEALTH CENTER IN INDONESIA
}

\author{
PUJI LESTARI HERYADI, RANI SAURIASARI*, RETNOSARI ANDRAJATI
}

Department of Pharmacy, Faculty of Pharmacy, Universitas Indonesia, Depok, Indonesia. Email: rani@farmasi.ui.ac.id

Received: 20 April 2017, Revised and Accepted: 13 July 2017

ABSTRACT

Objectives: Anemia during pregnancy is a common problem among women. Iron deficiency can result from low compliance to consuming iron supplement tablets (ISTs) as well as consumption patterns that may affect iron uptake. The purpose of this study was to provide knowledge regarding anemia during pregnancy, to increase adherence to consumption of IST, and to improve IST consumption patterns.

Methods: The study design was experimental with a randomized pre-post control design. There were 192 respondents who were divided into two groups: 96 respondents were not counseled and 96 respondents had received media leaflet counseling. The research was conducted at the community health center (CHC) of the Pagedangan Sub-district, Tangerang District, and Banten Province. All respondents were interviewed, and the hemoglobin $(\mathrm{Hb})$ value was examined using the Hemocue $\mathrm{Hb} 301$ Analyzer photometry method.

Results: The results were analyzed using a Chi-square test to assess significant differences between the two groups (p<0.05) and multivariate analysis was conducted using binary logistic regression. The results showed that the influence of counseling could increase the Hb value by 8.6 times compared to the non-counseling group ( $\mathrm{OR}=8.6$; $\mathrm{p}<0.05$ ) after controlling for number of IST per month, consumption pattern of IST with calcium, consumption pattern of IST with foods/beverages that inhibit the absorption of iron, level of education, and gestational age.

Conclusions: Gestational age in the third trimester tends to increase the Hb value by 5.1 times compared with the first- and second-trimester gestations $(\mathrm{OR}=5.1, \mathrm{p}<0.05)$. Thus, counseling from pharmacists can improve the success of anemia treatment in pregnant women in the $\mathrm{CHC}$ of the Pagedangan Sub-district, Tangerang District.

Keywords: Anemia, Counseling, Pregnancy women.

(C) 2017 The Authors. Published by Innovare Academic Sciences Pvt Ltd.This is an open access article under the CC BY license (http://creativecommons. org/licenses/by/4. 0/) DOI: http://dx.doi.org/10.22159/ajpcr.2017.v10s5.23111

\section{INTRODUCTION}

Anemia is a global health problem in both developing and developed countries and can affect health across all socioeconomic groups. The prevalence of anemia is highest among pregnant women (41.8\%) and children (69\%). Anemia in pregnant women falls into the category of serious health problems [1]. According to the World Health Organization (WHO), 32.8\% of pregnant women experience iron deficiency anemia, and the prevalence of anemia in Southeast Asia is quite high (48.2\%) [1]. In 2006, the WHO used data based on regression to estimate that $44.3 \%$ of Indonesians suffer from anemia [1]. The result of the Indonesian Health Survey in 2013 showed that $37.1 \%$ of pregnant women were anemic. According to the Ministry of Health (MoH) in 1999, the proportion of pregnant women with anemia in Indonesia is almost the same in urban $(36.4 \%)$ and rural $(37.8 \%)$ areas [2].

Anemia during pregnancy is associated with bleeding, a high maternal mortality of $20-25 \%$ low birth weight recurrent infection during the first 1000 days of birth, $37.2 \%$ stunting in children under the age of 5 years, a child who is overweight, and wasting (thin child) [2]. Anemia is prevalent in pregnant Indonesian women because women do not routinely consume the 90 blood booster tablets administered by the government (low compliance) although the Indonesian government has proclaimed the presence of a blood supplementation tablet program since the 1980s. According to the Indonesian health survey data, in 2013 , only $33.3 \%$ of pregnant women consumed the iron supplement tablets (ISTs) during pregnancy. Another reason for the prevalence of anemia in pregnant Indonesian women is the lack of knowledge among pregnant women regarding consumption patterns of IST with foods/ beverages that can inhibit iron absorption uptake.
The number of pregnant women who received iron (Fe) tablets in 2014 in the Banten province was only about $61.4 \%$ lower than the national data figure of $85.1 \%$ [3]. According to the Indonesian Health Survey, in 2012, 74\% of pregnant women in Banten Province had taken IST during pregnancy, while only $32 \%$ of pregnant women had taken the 90 IST during pregnancy [4]. In Tangerang City, 85.7\% of pregnant women received a sufficient amount of the 90 IST (Fe), this figure did not align with the incidence of a pregnant woman with anemia reported by the community health center (CHC) in Batuceper, which was $47.9 \%$ [5]. This data suggests that it is necessary to improve compliance to taking IST among pregnant women. Studies in Vadodara, India, show that periodic counseling, motivation, and strengthening by health personnel routinely increases compliance to iron tablet consumption [6].

Although pharmaceutical services were initially drug-oriented, they are now moving toward being more patient-oriented by offering services such as comprehensive pharmaceutical care [7]. Pharmaceutical care is a form of service that is committed to improving patients' quality of life. Counseling is a clinical pharmacy service that aims to improve a patient's knowledge and understanding of a drug as well as to provide methods for solving a patient's problem regarding a drug [7]. Counseling is a part of the patient and health-care communications conducted by clinical and community pharmacists and has proven to be quite useful for improving patient compliance [8]. Counseling regarding anemia during pregnancy can include describing how anemia is caused by obedience factors in the consumption of IST and describing the benefits of hemoglobin $(\mathrm{Hb})$ examination during pregnancy as well as the consequences of not curing anemia during pregnancy. This study examines the influence of apothecary counseling that aimed to increase 
$\mathrm{Hb}$ in pregnant women. The research was conducted at the $\mathrm{CHC}$ of the Pagedangan Sub-district, Tangerang District.

\section{METHODS}

This study used an experimental design with independent groups (pre-post design), which measured $\mathrm{Hb}$ level value before and after the intervention. In this design, the respondents were divided into groups: No counseling and counseling with a media leaflet. The data were obtained prospectively, and sampling was conducted using a randomized pre-post control design. The sample population in this study was all pregnant women who were examined at the CHC of the Pagedangan Sub-district, Tangerang District. Respondents were included in the study if they met all of the following inclusion criteria: Pregnant women who received Antenatal Care and were examined at the CHC of the Pagedangan Sub-district, Tangerang District; women in the first, second, or third trimester of pregnancy; women of ages I, II, or III; and women who received IST through the government program. Respondents who were at 9 months of gestation and/or had HIV/AIDS comorbidities, epilepsy, intestinal worms, thalassemia, and other blood disorders were excluded from the study. Respondents could resign from participating in the study at any time without needing to obtain the researcher's permission.

The respondents consisted of two groups: Those who did not receive counseling and those who did receive counseling. All respondents in both groups performed pre-test, which involved measuring their $\mathrm{Hb}$ value and responding to a preliminary questionnaire. A post-test was done after the respondents received no intervention or the intervention. All respondents' $\mathrm{Hb}$ levels were measured using the Hbocue 301 Analyzer $\mathrm{Hb}$, a Swedish production. The level of respondents' compliance was determined by calculating the number of residual IST that had been given to know the number of IST that had been consumed for 30 days. Determining the consumption patterns of calcium and IST and consumption/food intake patterns that inhibited iron uptake was done before and after the intervention in the counseling group, whereas in the non-counseling group this was performed after 30 days of observation. All the results were analyzed using univariate analysis to obtain the frequency distribution and proportions. For the bivariate analysis using Chi-square and the multivariate test using Binary logistic regression, all data were analyzed and evaluated using SPSS V.23. A research permit was granted by the Tangerang District Health Department (No.423.6/591.Dinkes), and the study passed the ethics test of FKUI-RSCM N0. 968/UN2.F1/ETIK 2016.

\section{RESULTS}

This research was conducted at the $\mathrm{CHC}$ of the Pagedangan Sub-district, Tangerang District and covered 13 Villages: Karang Tengah, Central Malang, Jatake, Situ Gadung, Kadu Sirung, Cicalengka, Pagedangan/ Puspiptek, Cicayur, Lengkong Kulon, Cihuni, Cijantra, Medang-Anggrek, and Medang-Cempaka. The area covered by the $\mathrm{CHC}$ is $464,607 \mathrm{Ha}$, and the Pagedangan CHC covers 86 integrated post [9]. Its facilities include general health, dental health, pediatric health, maternal and child health, immunization, TB services, Sexually-transmitted infection services, nutrition consultation, visual inspection of acid, geriatric services, leprosy services, and laboratory services. In this study, the respondents were divided into two groups: Non-counseling and counseling. The women's sociodemographic characteristics are provided in Table 1.

The Chi-square analysis indicated the differences between the two groups. The gestational age did not differ significantly between the two groups $(p>0.05)$. In this study, most of the pregnant women visited the CHC during their third trimester of pregnancy (46.88\%). Mother's age was divided into two groups: 21-35 years old is not at risk while $<21$ years and $>35$ years is risky. Maternal age between the two groups did not differ significantly $(p>0.05)$. In the noncounseling group, 16 respondents (16.7\%) were at a risky age, and 80 respondents were at a not risky maternal age (83.3\%). In the counseling group, 75 respondents were at a risky age $(78.1 \%)$ and 21 respondents were at a not risky age (21.9\%). The education level between the two groups was not significantly different $(p>0.05)$. Almost all of the respondents were junior high school graduates with a total of 90 respondents (46.9\%), and 48 respondents were high school graduates $(25 \%)$. The level of education affected respondents' use of health services and iron consumption for increasing $\mathrm{Hb}$ value during pregnancy [10]. A high education level indicates that respondents are ready to receive information and knowledge given by the counselor. According to $\mathrm{MoH}$ [7], the higher the education level, the lower the prevalence of anemia. According to the results of the current study, the

Table 1: Respondents' sociodemographic data

\begin{tabular}{|c|c|c|c|}
\hline Characteristics & Non-counseling n=96 (100\%) & Counseling n=96 (100\%) & p-value \\
\hline \multicolumn{4}{|l|}{ Gestational age } \\
\hline $1^{\text {st }}$ trimester & $21(21.9)$ & $20(20.8)$ & \multirow[t]{3}{*}{0.110} \\
\hline $2^{\text {nd }}$ trimester & $24(25)$ & $37(38.5)$ & \\
\hline $3^{\text {rd }}$ trimester & $51(53.1)$ & $39(40.6)$ & \\
\hline \multicolumn{4}{|l|}{ Mother's age } \\
\hline Not at risk (21-35 years) & $80(83.3)$ & 75 (78.1) & \multirow[t]{2}{*}{0.460} \\
\hline Risky $(<21$ years or $>35$ years $)$ & $16(16.7)$ & $21(21.9)$ & \\
\hline \multicolumn{4}{|l|}{ Level of education } \\
\hline Not completed primary school & $2(2.1)$ & $3(3)$ & \multirow[t]{6}{*}{0.230} \\
\hline Primary school graduate & $22(22.9)$ & $18(18.8)$ & \\
\hline Junior high school graduate & $48(50)$ & $42(43.8)$ & \\
\hline Senior high school graduate & $23(24)$ & $25(26)$ & \\
\hline Associate's degree graduate & 0 & $4(4.2)$ & \\
\hline Bachelor's degree graduate & $1(1)$ & $4(4.2)$ & \\
\hline \multicolumn{4}{|c|}{ The duration of calcium consumption with IST } \\
\hline At the same time & $47(49.0)$ & 0 & \multirow[t]{2}{*}{$<0.001$} \\
\hline Not at the same time & $49(51.0)$ & $96(100)$ & \\
\hline \multicolumn{4}{|c|}{ Along with food/beverage inhibiting iron absorption } \\
\hline Not at the same time & $82(85.4)$ & $93(96.9)$ & \multirow[t]{2}{*}{0.009} \\
\hline At the same time & $14(14.6)$ & $3(3.1)$ & \\
\hline \multicolumn{4}{|l|}{ Number of IST per month } \\
\hline $0-15$ tablet & $42(43.8)$ & $13(13.5)$ & \multirow[t]{5}{*}{$<0.001$} \\
\hline $16-30$ tablet & $51(53.1)$ & $20(20.8)$ & \\
\hline $31-45$ tablet & $2(2.1)$ & $47(49.0)$ & \\
\hline $46-60$ tablet & $1(1.0)$ & $16(16.7)$ & \\
\hline Total & $96(100)$ & $96(100)$ & \\
\hline
\end{tabular}


higher the education level the pregnant woman has, the higher her level of compliance is to taking IST [11]. The respondents' clinical results are organized by the amount of consumed IST, consumption patterns between calcium tablets and IST, and consumption patterns of food/ beverages that can inhibit the absorption of iron, as shown in Table 1.

The results showed that consumption of IST was significantly different in both groups $(\mathrm{p}<0.05)$. This suggests that counseling can increase a pregnant woman's awareness to consume IST compared to women who are not counseled. The number of IST given is expected to increase the value of $\mathrm{Hb}$. According to Indonesia health survey [2], the minimum recommended consumption of IST is 90 tablets during pregnancy. IST with a Ferrous Fumarate composition is equivalent to $60 \mathrm{mg}$ of iron. Counseling affects the amount of IST consumed, thus increasing the $\mathrm{Hb}$ value. The percentages of women in the group that was not counseled who consumed IST in the different ranges were as follows: 0-15 tablets, $43.8 \%$; $16-30$ tablets, $53.1 \%$; $31-45$ tablets, $2.1 \%$; and 46-60 tablets, $1.0 \%$. In the counseling group, the percentages were as follows: $0-15$ tablets, $13.5 \%$; $16-30$ tablets, $20.8 \%$; $31-45$ tablets, $49.0 \%$; and $46-60$ tablets, $16.7 \%$. According to the $\mathrm{MoH}$, the number of blood booster tablets recommended by the government is at least 90 tablets during pregnancy. The patient compliance to the consumption of IST in Indonesia is still very low due to lack of knowledge regarding IST, iron absorption factors, and eating foods that can interfere with iron uptake [12]. The differences in consumption patterns of calcium tablets and IST in pregnant women were significantly different between the two groups $(\mathrm{p}<0.05)$. Counseling affects calcium consumption patterns as well as iron consumption patterns. In the counseling group, calcium was consumed together with IST that were given 1-2 hrs before. The non-counseling group indicated 47 respondents (49.0\%) who consumed calcium together with IST 49 respondents (51.0\%) demonstrated a consumption pattern in which the calcium and iron consumption was not simultaneous. Table 2 summarizes the average consumption pattern of calcium tablets and IST in both groups.

The consumption pattern of calcium and IST was significantly different between the before and after intervention conditions in the counseling group $(\mathrm{p}<0.05)$, whereas the consumption pattern of calcium and IST did not differ significantly in the non-counseling group ( $p>0.05)$. The pattern of consumption in the counseling group is different because respondents have been given knowledge and education so that incorrect habits can be improved. Calcium is a supplement given during pregnancy that is useful for bone growth in the fetus. However, $300 \mathrm{mg}-600 \mathrm{mg}$ of calcium consumed along with iron interferes with heme iron absorption by $40 \%$ [13]. The $\mathrm{Ca}^{2+}$ mechanism that inhibits the uptake of $\mathrm{Fe}^{2+}$ remains unclear [14]. The initial dose of calcium can inhibit heme iron by $50 \mathrm{mg}$ [13]. The effect of iron inhibition occurs during the transport phase of iron across the basolateral membrane from enterocytes to plasma [15]. Iron absorption involves the hDMT1 transporter; the action of this transporter can be inhibited in the presence of $\mathrm{Ca}^{2+}$. $\mathrm{Ca}^{2+}$ inhibits $\mathrm{Fe}^{2+}$ in a non-competitive manner with low affinity [13]. The food/beverage consumption pattern can affect iron absorption. In the research result, the consumption pattern was significantly different

Table 2: Calcium tablet and iron supplement tablet consumption patterns in both groups

\begin{tabular}{llll}
\hline Groups & Before & After & p-value \\
\hline $\begin{array}{l}\text { Calcium and IST } \\
\text { consumption pattern }\end{array}$ & & & \\
$\quad$ Counseling & $0.38 \pm 0.49$ & $1.0 \pm 0.0$ & $<0.001$ \\
$\quad$ Non-counseling & $0.51 \pm 0.5$ & $0.51 \pm 0.5$ & 1.00 \\
Food consumption pattern & & & \\
along with IST & & & \\
$\quad$ Counseling & $0.27 \pm 0.45$ & $0.03 \pm 0.17$ & $<0.001$ \\
$\quad$ Non-counseling & $0.15 \pm 0.35$ & $0.15 \pm 0.35$ & 1.00 \\
Hb Value (g/dL) & & & \\
$\quad$ Counseling & $10.39 \pm 1.24$ & $11.52 \pm 0.92$ & $<0.001$ \\
$\quad$ Non-counseling & $11.21 \pm 1.24$ & $11.28 \pm 11.53$ & 0.300 \\
\hline
\end{tabular}

between the two groups $(\mathrm{p}<0.05)$. This is because the counseling group is given knowledge regarding anemia and the food/beverage interactions that can inhibit iron absorption, unlike the non-counseling group. The food that can inhibit iron absorption includes milk or dairy products and tea. Table 2 summarizes differences in consumption patterns of foods/ beverages that interfere with iron uptake in both groups.

The pattern of food/beverage intake that interfered with iron uptake was significantly different between before and after intervention in the counseling group $(p<0.05)$, whereas the pattern did not differ significantly between before and after in the non-counseling group ( $>0.05)$. In the counseling group, 93 respondents (96.9\%) did not simultaneously consume food/beverages that inhibit iron uptake, while 3 respondents (3.1\%) did engage in concurrent consumption. In the non-counseling group, 82 respondents (85.4\%) took time between taking the IST and consuming drinks such as tea and milk, while 14 respondents $(14.6 \%)$ did not take time between taking the IST and consuming drinks such as tea and milk. Foods/beverages containing polyphenols can inhibit heme iron uptake by forming chelates with iron. Epigallocatechin-3-gallate inhibits absorption by decreasing iron expenditure from basolateral membranes [16]. One cup of tea (200 mL) can inhibit $75-80 \%$ of iron uptake while one cup of coffee can reduce iron absorption by $60 \%$ [13]. Pharmacist counseling services is a discussion activity between pharmacists and pregnant women in which the former provides support and encouragement so that the latter gains confidence in problem-solving. Drug counseling is a form of education that determines how well a respondent understands the importance of IST consumption for minimizing the incidence of anemia in pregnancy. Counseling is a gold standard in providing information and is effective in providing good outcomes. Pharmacist counseling was conducted by researchers at the $\mathrm{CHC}$ with the help of leaflet media. Counseling services are actively initiated by the pharmacist. Counseling can reduce non-compliance in the use of IST supplements as well as IST consumption patterns that can inhibit iron uptake. The method for improving compliance included communication, providing appropriate information, and preventing non-compliance [7]. Counseling can improve respondents' compliance to consume IST, and the increase in consumption of IST increases the value of $\mathrm{Hb}$ in pregnant women. Table 2 summarizes the average pretest-posttest values of the two groups.

The mean $\mathrm{Hb}$ value was significantly different $(\mathrm{p}<0.05)$ between before and after pharmacist counseling with an increase of $1.13 \mathrm{~g} / \mathrm{dL}$. In the group that did not receive counseling, the $\mathrm{Hb}$ value did not differ significantly between before and after $(p>0.05)$. Multivariate analysis was conducted to determine the most influential factor in the changes of $\mathrm{Hb}$ value. In this research, binary logistic regression analysis was performed. Based on the results of the test, the group subjected to counseling had an increase of 8.6 times when compared with the group that was not subject to counseling after controlling for number of IST per month, consumption pattern of IST with calcium, IST consumption pattern with food/beverage that inhibited the absorption of iron, education level, and gestational age. These results suggest that pharmacist counseling may increase $\mathrm{Hb}$ value during pregnancy. Gestational age in the third trimester tends to increase the Hb value by 5.1 times when compared with the first- and second-trimester gestations $(\mathrm{OR}=5.1, \mathrm{p}<0.05)$. This is due to the increased awareness of the woman regarding the importance of maintaining a high $\mathrm{Hb}$ value before giving birth. Enhancement of the $\mathrm{Hb}$ value in the third trimester determines the weight of the baby because the fastest growth occurs during this trimester, thus increasing the need for iron and other micronutrients. The incidence of anemia occurring in the third trimester increases the chances of low birth weight infants by $6.5 \%$ and premature birth by $11.5 \%$ compared to the incidence of anemia in the first- and second-trimesters [17].

\section{CONCLUSION}

This study showed that pharmacist counseling may help increase $\mathrm{Hb}$ value during pregnancy. Further, studies are warranted to develop effective interventions. 


\section{REFERENCES}

1. de Benoist B, McLean E, Egli I, Cogswell M. Worldwide Prevalence of Anaemia 1993-2005: WHO Global Database on Anaemia. Geneva: WHO; 2008

2. Indonesian Ministry of Health. Health Research and Development Unit. Basic Health Survey 2013. Jakarta: Indonesian Ministry of Health; 2013.

3. Indonesian Ministry of Health. Indonesian Health Profile 2014. Jakarta: Indonesian Ministry of Health; 2014.

4. Indonesian Ministry of Health. Indonesian Health and Demographic Survey 2012. Jakarta: Indonesian Ministry of Health RI; 2013.

5. Health Department Tangerang City. Report of Nutrition Program 2013. Tangerang, Indonesia: Health Department Tangerang City; 2014.

6. Ghanekar J, Kanani S, Patel S. Toward better compliance with ironfolic acid supplements: Understanding the behavior of poor urban pregnant women through ethnographic decision models in Vadodara, India. Food Nutr Bull 2002;23(1):65-72.

7. Indonesian Ministry of Health. Guidance of Pharmaeutical Service Conseling in Health Care Provider. Jakarta: Indonesian Ministry of Health; 2007.

8. Wati MR, Mustofa PI. Effect of community pharmacists' counseling on hypertensive patients. J Manajemen Pelayanan Farmasi 2015;5(1):48-55.
9. Indonesian Ministry of Health. Basic Data Community Health Center Banten Disctrict. Jakarta: Indonesian Ministry of Health; 2014.

10. Chowdhury HA, Ahmed KR, Jebunessa F, Akter J, Hossain S, Shahjahan M. Factors associated with maternal anaemia among pregnant women in Dhaka city. BMC Womens Health 2015;15:77.

11. Aditianti A, Permanasari Y, Julianti ED. Companion for drinking bloodboosting tablets (IST) can improve IST consumption compliance on anemic pregnant women. J Penelitian Gizi Makanan 2015;38(1):71-8.

12. Indonesian Ministry of Health. Guidance on Blood Supplement Tablet Program. Jakarta: Indonesian Ministry of Health RI; 2015.

13. Scheers N. Regulatory effects of $\mathrm{Cu}, \mathrm{Zn}$, and $\mathrm{Ca}$ on $\mathrm{Fe}$ absorption: The intricate play between nutrient transporters. Nutrients 2013;5(3):957-70.

14. Hallberg L, Hulthén L. Prediction of dietary iron absorption: An algorithm for calculating absorption and bioavailability of dietary iron. Am J Clin Nutr 2000;71(5):1147-60.

15. Hurrell R, Egli I. Iron bioavailability and dietary reference values. Am J Clin Nutr 2010;91(5):1461S-7.

16. Ma Q, Kim EY, Lindsay EA, Han O. Bioactive dietary polyphenols inhibit heme iron absorption in a-dose dependent manner in human intestinal caco2-cells. J Food Sci 2011;76(5):H143-50.

17. Kumar KJ, Asha N, Murthy DS, Sujatha M, Manjunath V. Maternal anemia in various trimesters and its effect on newborn weight and maturity: An observational study. Int J Prev Med 2013;4(2):193-9. 